\title{
Wanting To Live Here: Design After Anthropocentric Functionalism
}

\author{
Jeffrey Bardzell \\ Pennsylvania State University, State \\ College, PA., USA
}

\author{
Shaowen Bardzell \\ Pennsylvania State University, State \\ College, PA., USA
}

\author{
Ann Light \\ University of Sussex, Brighton, UK, \\ Malmö University, Malmö, Sweden
}

\begin{abstract}
Design research has recently turned to theoretical perspectives, including care ethics and posthumanism, to counter the industrial processes that have led to climate crisis. As design theorists and ethnographers of interaction, we researched experimental ecofarming in a community that shared many of these theoretical and ideological commitments. Our goal was not to offer an account of use and provide design implications in support of it. Instead, we chose to identify concrete practices and artifacts that embody the sorts of industrial transformations that we are seeking-even if they are manifest in an imperfect or partial form. We encountered practices focused on community building, local resilience to climate disruptions, experiments in eco-farming, economic survival, and attracting the next generation. One interlocutor translated these concerns into a simple binary, asking, "do we want to live here?" This paper contributes to a design research agenda that might (eventually) provide an affirmative answer.
\end{abstract}

\section{CCS CONCEPTS}

- Human-centered computing; • Human computer interaction (HCI); • HCI theory, concepts and models;

\section{KEYWORDS}

HCI theory, design theory, climate, sustainability, care ethics, place, emplacement, transformation, agriculture, design critique, essay

ACM Reference Format:

Jeffrey Bardzell, Shaowen Bardzell, and Ann Light. 2021. Wanting To Live Here: Design After Anthropocentric Functionalism. In CHI Conference on Human Factors in Computing Systems (CHI '21), May 08-13, 2021, Yokohama, Japan. ACM, New York, NY, USA, 15 pages. https://doi.org/10.1145/3411764. 3445167

\section{INTRODUCTION}

The planet is facing ecological crisis. Industrialization-a practice that combines mass production, distribution, and consumption; the extraction of physical materials and economic value from people and places; and the development of systems and logistics that maintain and extend these activities-is heavily implicated in that crisis. $\mathrm{HCI}$ is one discipline among many that reflects and perpetuates

Permission to make digital or hard copies of all or part of this work for personal or classroom use is granted without fee provided that copies are not made or distributed for profit or commercial advantage and that copies bear this notice and the full citation on the first page. Copyrights for components of this work owned by others than the author(s) must be honored. Abstracting with credit is permitted. To copy otherwise, or republish, to post on servers or to redistribute to lists, requires prior specific permission and/or a fee. Request permissions from permissions@acm.org.

CHI '21, May 08-13, 2021, Yokohama, Japan

(c) 2021 Copyright held by the owner/author(s). Publication rights licensed to ACM. ACM ISBN 978-1-4503-8096-6/21/05 . .\$15.00

https://doi.org/10.1145/3411764.3445167 industrial practices. Today, what once looked like clever subjugation of natural phenomena enabled by rapidly developing science disciplines, is now recognized as bad husbandry and poor justice, ushering in climate emergency and irreversible, life-threatening planetary changes [54].

Even so, much design work continues with little thought to where this trajectory will lead. Even people worried about unsustainable futures go to work and contribute to that unsustainability, their agency no match for the wider material and discursive practices of designing [57]. Calls for sustainability in HCI go back at least a dozen years (e.g., [12]), and have led to research on tools that make individuals more aware of their own consumption or facilitate the distribution of energy use away from peak times. The growing movement of SCHI [12, 13, 44, 58, 67, 80, 81, 95, 105] has now congregated round the need for total system change (though many of its writings are cautionary rather than offering alternative methodology or process). They advocate that, like other disciplines connected to industrial development, HCI must do more than help individual consumers tweak behaviors. Small adjustments, rather than transformative thinking, to be seen in agendas worldwide, falls under what Fry calls "sustaining the unsustainable": that is, merely delaying catastrophe [35] (a little). We align with movements in SHCI that look beyond protecting current economic, social and environmental relations [58, 80, 95], but seek renewal for ethical reasons - there are fairer and healthier ways to co-exist - and practical reasons - already baked-in Anthropocene changes will demand radical changes in lifestyle.

In other words, the whole system of production, distribution, and consumption must change, in line with values other than the pursuit of economic growth. We need "a significant reorientation of design from the functionalist, rationalistic, and industrial traditions from which it emerged, and within which it still functions at ease, towards a type of rationality and set of practices attuned to the relational dimension of life" ([32], p42). We note that, historically, HCI has supported industry goals. We also recognize that functionalism has always informed design, as evident in Simon's classic formulation: "To design is to devise courses of action aimed at changing existing situations into preferred ones" [95], or the ubiquity of the maxim, "form follows function." So, we see HCI as in a bind: we need to be designerly enough to rethink and remake our world, but an element most in need of change is the nature of designing itself. What we are calling "anthropocentric functionalism"-the pursuit of efficiency and a human-centered appropriation of the world's resources-lies at the heart of what has been wrong with design, so we will need an alternative-an alternative that operates cohesively at the levels of theory, ideology, and practice.

As with others in $\mathrm{HCI}$ and design, we have been reading from care ethics $[11,89,90]$, posthumanism $[45,46,89,103,104,108]$, 
and ecofeminism $[111,112]$, finding in them ideas and provocations that seem to suggest an alternative to anthropocentric functionalism. Yet reading theory in search of alternatives is one thing; actually transforming industrial production, distribution, and consumption is altogether different. Such a transformation will likely require years if not decades of experimentation with new modelsall while still maintaining economies and quality of life. Scoped to our discipline-human-computer interaction design-we have seen some early projects, but transforming the field's research and development practices along these lines has barely begun: the project is almost too large to imagine, even as new technological developments in artificial intelligence and cloud computing race ahead. Whatever the practical alternative to anthropocentric functionalism is in HCI, it cannot be deduced from a collection of readings.

As a research field, $\mathrm{HCI}$ often advances through encounters with instances of practice connected to designing and making, from Carroll and Kellogg's design "artifact as theory-nexus" [19] to Research through Design $[4,116]$ and more recently critical and speculative design $[2,30]$. As authors, we have worked separately and together in the past, researching creativity support tools, making, and participatory design. We have seen how certain individual cases-design artifacts and the stories of their creation and usehave had strong impacts on the advancement of HCI theory, from the study of Wikipedia as a paradigm example in the theorization of collective intelligence to the role of the 3D printer in story of the maker movement. We realized that reimagining $\mathrm{HCI}$ along the lines proposed in care ethics, posthumanist, and ecofeminist theories would likely unfold in conjunction with many cases. The present essay expresses our efforts to engage a few such cases in the hope of enriching the field's theoretical repertoire as to what a post-anthropocentric-functionalist HCI might look like. A key take-home of this work is to encourage $\mathrm{HCI}$ to engage with restorative agricultural research and practice not just as a domain that can benefit from better IT systems, but also as a research field that takes stewardship of the biosphere seriously and has an inherent connection to land and place.

In this respect, we see agricultural practices as both a topic of study for applying HCI and a helpful analogy, for, in needing redesign, $\mathrm{HCI}$ is far from alone. We note that agriculture-another industrialized domain of production-is facing the same issues. Agriculture requires intervention: it is tied to environmental unsustainability and, if/when it fails, it leads to mass starvation and political instability (c.f., Syria's refugee crisis). Yet agriculture is also a site of hope, for two reasons. First, its relatively low barriers to entry and openness to experimentation makes it amenable to widespread, bottom-up discovery. Second, its connectedness with the soil literally and figuratively grounds innovation practices in the links between human and non-human processes and health. Thus, in its positioning as a "human-centered" practice that both causes and suffers from climate change, which also supports histories of experimental innovation and alternative practices, agriculture might offer cases that can inform our efforts in HCI to pursue a more sustainable field. For, as in HCI, agriculture's narrow focus has made it vulnerable to contributing to long-term violation of the qualities in the world that humans and other life need to flourish, even as it operates short-term optimization processes.
As ethnographers of interaction, we researched experimental ecofarming in a community in Taiwan that appeared to share many of the same theoretical and ideological commitments expressed in care ethics, posthumanism, and ecofeminism; indeed, some members in that community were engaging with these readings themselves. We wanted to use our ethnographic work as a material to think with. In other words, the goal of our ethnography was not to offer an account of use that might inform technological development to support such use (e.g., to develop software that helps farmers predict crop yields). Instead, our goal was to identify concrete practices and artifacts that embody the sorts of industrial transformations that we are seeking-even if they are manifest in an imperfect or partial form-akin to a methodology used elsewhere in HCI (e.g., $[6,70])$ and evocative of Cooper's everyday utopias [25]. The goal is not to find a viable solution (convenient as that would be) but rather to discover new connections, juxtapositions, framings, etc., that might help us picture and pursue alternatives to the present. Beyond our general appeal to engage with restorative agriculture, our research suggests three interrelated implications:

- HCI researchers and practitioners should more intentionally design resources that are place-based and sharable by all those who share the space, i.e., relational assets $[65,66]$.

- HCI should fully leverage its own resources to advance the field-not to retreat into a nostalgic past-so as to support flourishing biosystems.

- HCI designers should factor land usage and interspecies relations into any consideration of IT development and deployment.

These implications are ideological as well as methodological. One of our interlocutors posed a question that got at the heart of our project, when she wondered "whether one has the desire to live here." Wanting to live here captures a range of issues central to life: it is an ongoing confidence in having enough to eat, finding work that is meaningful and appropriately compensated, identifying like-minded people to move amongst, having adequate shelter from extreme weather events and its effects, living according to one's values and cultural traditions, having opportunities to grow, enjoying natural scenery and open spaces. It reflects a desire in us to have space for flourishing rather than sheer survival. It found resonance in one researcher's stated mission to ask, "how do we dwell together well and how might we do so better?" [62] Though the anthropocentric functionalism of the industrial revolution has helped to alleviate hunger and poverty while supporting a middle class, nonetheless its complicity in climate change, labor injustice, race and gender injustice, and disease spread has high costs: increasingly, communities don't "want to live here" (or literally cannot). In seeking to unpack and understand wanting to live here, we were brought back to the significance of place, which has long been an important theme in HCI, reflected in the influential paper [47] that critiqued the notion of space as a container in which things happen, to emphasize the social and semantic significances of place, and defined place for a generation of HCI. Subsequent work has problematized these relations further [22, 29, 68], but much has considered this in an urban context. Our work led us to a more physical and material conception of place: the ways that human bodies are disposed alongside animal, plant, and microbiological bodies as 
collaborators, bystanders, competitors, resources, enemies-and how these shape living practices, from sustaining oneself to doing engineering. In short, our work suggests that, informed by restorative agriculture, $\mathrm{HCI}$ might orient itself more intentionally towards developing and/or supporting place-based common resources (and the "relational assets" that emanate from them); that HCI research should be forward-looking and anti-nostalgic, so as to play to and further develop its disciplinary strengths better aligned with sustainability goals; and that land-use and more-than-human relations (including underlying infrastructure, such as server farms and mineral extraction) should be a consideration for future platform and system design. Doing so better aligns HCI with the broader imperative of "wanting to live here."

\section{BACKGROUND}

Concern for the course of HCI is not new; the discipline evolves swiftly and one of its historical strengths, we believe, has been its self-awareness and reflexivity. HCI self-critiques manifest in a long history of books and papers that identify and challenge fundamental assumptions about the field, including its ties to rationalism, individualism, and work. At a time when HCI's alignments with capitalist consumption are being widely questioned as contributing toward climate crisis, we build on that tradition of self-critique, even considering whether the discipline should have a future.

\subsection{Doing and Undoing Human-Centered Design}

An early theme in HCI was the importance of human-centered approaches in the face of a technology-centered industry [83]. The mantra of efficiency, effectiveness, and satisfaction in use became enshrined in standards (ISO 9241-11). Yet critiques of HCI's rationalism came swiftly (e.g., $[1,93,102,114])$ and have recurred ever since. Pleasure and experience joined ease-of-use (e.g., [14, 76]) and the humanities were invoked [2]. "Third-wave HCI" [17, 47] confronted HCI's failure to address sociality and aesthetics.

However, though a broader understanding of affective dimensions developed, nothing fundamentally altered the anthropocentric focus, further cementing $\mathrm{HCI}$ in service to economic growth agendas. Light [60] observes that HCI is "dependent on technology-led research councils and industry for its continued freedom to practice - and which is often validated by its relation to successful R\&D" (p431). Yet, little has been said, within the field, about its overly close ties to economic development and capital (e.g., consumerism). Even Dunne \& Raby's speculations, using design to reflect on the harms of global commerce and capitalist regimens [29], are criticized for neoliberal individualism [105].

More recently, a number of $\mathrm{HCI}$ voices have critiqued design for its environmental failures [12, 20, 100], including the economic basis of the design industry [80], and argued to replace exploitative practices with humanity, decency and respect $[61,67,72]$, with the need to introduce alternatives to the control paradigm [73]. Concerns have been raised, too, about the ideology informing HCI, which began by infusing prospective environmental solutions with the same narrow Modern horizon that dominates the mainstream [28]. Likewise, Fry [35] warns that "Change cannot and should not be reduced to instrumental actions" ( $\mathrm{p} 4)$; the change he calls for is nothing short of a transformation in all our political processes and our understanding of ourselves to avoid "defuturing" the world (p10). Now, even the human-centeredness of a field constituted to study humans in relation to machinery has been challenged from within. New work (e.g. [34, 50, 62, 97]) offers proposals to de-center design. In all of this, we see the beginning of a new, more ecological, thinking, though the pathways to significant impact on the mainstream remain unclear.

\subsection{Alternatives to Anthropocentric Functionalism}

Along with others in HCI, we draw from theories of posthumanism and care ethics as part of our contribution to the project of reimagining $\mathrm{HCI}$ and design. Posthumanism expands the circle of moral concern, extending subjectivities beyond the human species. Forlano [34] links posthumanism to design, invoking "critical race theory and decolonial theory to consider how emergent design perspectives might better support values such as equality and justice for humans and nonhumans that have been traditionally ignored in design processes" (p16). Smith et al. [97] consider ways that design can support interspecies cohabitation on an urbanizing planet, leveraging concepts of "natureculture" and "hybrids" from feminist technoscience and STS. Liu et al. introduce the concept of collaborative survival and envision how HCI might support it via tactics of engagement, attunement, and expansion [74].

Prominent in inspiring a new wave of design is Haraway's Staying with the Trouble [46], which builds on Whitehead's notion that "Beings do not pre-exist their relatings" (p6). Haraway describes humans as "companion species" co-existing with billions of symbionts, not least in our bodies. Puig de la Bellacasa [90], combines ecological thinking, with its emphasis on de-centering the human, with care ethics. She borrows from Star and Ruhleder [98] to discuss infrastructural break-down, the moment when hidden infrastructure becomes visible. Speaking of soil, she notes that the existence of fertilizer is proof that something has gone wrong-the soil is unable to nourish-and that chemical intervention both solves and perpetuates the problem: "if soil ecology was working and healthy, most of us could go just around without really noticing it. Noticing it is an event, what we do with that event is what matters: our responses are part of the relational infrastructural arrangement." [89].

Care ethics focuses on interdependence. Co-operation, not (the invisible hand of) competition, is the underlying organization of the living world, evident in all relations, preceding humans as a species. Benhabib [11] distinguishes between two forms of mutuality. The mutuality of justice ethics is based in formal reciprocity, such as the obligation that humans have to other humans, the mutuality of civic laws: I won't steal from you, and you won't steal from me. The mutuality of care ethics is concrete and particularized; it includes the obligations we have to others in virtue of their particularity-for example, a parent's particular response to the cries of an infant. Such ethics are complementary [11]: the infant cannot reciprocate at that stage of life. From this perspective, obligation is not a moral choice, but an intrinsic characteristic of existing [90]. Thus, care ethics is not an abstract question of how to formulate just laws, but acknowledgment of the indivisibility of all things, located in 
concrete physical relations that must be maintained through ongoing acts of care. Such ideas can inform the design of engagement strategies [64] and technological futures [5].

In addition to the critique of competition, this body of theory also critiques the extractive nature of contemporary production. Lent [59] ascribes a key role in creating exploitative relationships to Western cultural history of man-over-nature relations, patriarchy, and colonialism. Yusoff [115] and Hage [43] point out that racism and environmental exploitation are linked, by "a mode of inhabiting the world through dominating it for the purpose of making it yield value: material or symbolic forms of sustenance, comfort, aesthetic pleasure, and so on" ([43], p87). Morton places exploitation at the heart of agriculture, tracing the industrial and logistical programs built on it: "Toxic from the beginning, [industrial age] operates blindly like a computer program. The homology is tight since algorithms are now instrumental in increasing the reach ... Big data makes bigger farms" ([78], p42). Scott [94] refines this analysis, pointing out that the evolution of grain crops allowed mass subjugation, effectively an end to early ecological thinking for the communities that adopted grain.

Collectively, these writings point to ways that anthropocentric functionalism has introduced exploitative relations among humans (manifest as forms of social domination, including racism and misogyny) and the rest of the earth. These relations cut the ties of interdependence and cooperation, leading not only to environmental destruction but-as we will show-also foreclosing relationships and experiences that people find meaningful and fulfilling. Care ethics resists such dehumanizations by asserting and cherishing individuals as such, not as members of a class.

\subsection{Agricultural Research in HCI}

In the case studies below, we discuss how farmers-many of whom have relocated from cities and industrial professions, including software engineering-experiment with agricultural practices, new technologies, and alternative economics in the search for an economy of food production that marries care with the possibility of livelihood.

Agriculture, as a whole, is a particularly relevant domain of study for HCI and design. Not only is it a data intensive endeavor, using digital systems to report on conditions, manage logistics and optimize output, but it is a useful analogy for other functionalist systems. Agricultural research in HCI can be divided into studies that work within a conventional productivity paradigm and those that seek to challenge it. An example of the former, drawn from a development context where the economics suggest the practices of mainstream agriculture, is Oduor et al.'s [85] work in rural Kenya. There, rural farmers were interested in accessing farming information that increases yields (e.g., soil fertility, distribution of irrigation water, and sales opportunities); seeking to use ICT tools to support commercial viability. This resonates with a line of research on technology accessibility and adaption[41,79,99,110].

At the other end of the scale, DiSalvo and Jenkins [27] describe a system for alerting communities to the ripeness of fruit in the neighborhood to support foraging. Work in urban agriculture focuses on community engagement, collective activism, and citizen science [21, 49, 51, 84]. For example, Steup et al.'s [100] study shows that small-scale farmers collectively act as a "tiny public" to shift food sovereignty away from big supermarket chains to local food producers. Barbieri et al [10] consider the damage that the highly technologized practices of industrial agribusiness is doing, proposing a limits model and calling for a re-definition of success that embraces inefficiency and centers on both human nourishment and ecological flourishing (p72).

However, most studies place the relation between people and technology at the center of analysis, with a few exceptions: Raghavan et al. [91] turn to agroecology, a farming method using ecological principles (e.g. the flow of natural resources, the rhythm of growth) to produce high yields while reducing negative environmental impacts. Liu et al. [71] propose using permaculture working with nature to replace the traditional control model in industrial farming. Liu et al. leverage posthumanist concepts of noticing differently and companion species to unpack relations between human and nonhuman actors in their study of experimental farming practices [72]. In the present work, we are interested in unpacking mutuality as it manifests in interactions between human and nonhuman stakeholders, learning from these more careoriented practices, but using the studies here to analogize rather than offering them as the topic of transformation.

\section{ADVANCING THEORY USING ETHNOGRAPHY}

The authors of this essay have in the past separately focused on many of the central concerns of this essay-HCI and care, posthumanism, and environmental justice-and now come together to pool insights and perspectives. The result is a collaborative essay that critically engages $\mathrm{HCI}$ and seeks to contribute to agendas that reposition the field in light of environmental crisis. To support this project of making fundamental change in our field, we chose to examine a number of cases from fieldwork conducted by part of the research team, in which the whole team found phenomena that seemed to embody many of the practical, intellectual, and ideological values with which we were engaging.

The cases were drawn from ethnographic fieldwork conducted in Taiwan by two of the authors, who have been researching innovation there since 2011 , documented in $[7,8,36,37,70,71,73]$. In the context of this essay, we foreground ethnographic field research conducted in 2017 and 2018 in one farming village in rural Taiwan. Our focus on these cases relates to our concerns and we picked them from many others to show the rethinking of practice in the light of different conceptions as to how the world might be assembled. This sampling of cases acknowledges the theme of interest to the researchers-agricultural innovation-while accepting that a focus on a single area, as here, also involves some serendipity in the choice of the particular agriculturists to observe and interview. In this, it resembles other recent work to understand place-based socio-technical innovation [66]. However, we would argue that the small farms of Taiwan are a particularly fecund area for innovation because of Taiwan's complex international status, including its key role in global IT manufacturing, its complex relationships with the People's Republic of China and the United States, and its colonial histories involving Europe, China, and Japan. 
We do not go extensively into the methodology of data collection in this essay, since we do not recount these experiences and observations to make them replicable, but to show how thinking and acting relate when particular values are invoked. Instead, we describe how we decided these cases were relevant to our concerns and how we then conducted analysis together.

Including which Data: Our data included fieldnotes, photos, audio recordings, and artifact collections from farmlands that included flyers, catalogs, and booklets farmers created to promote their products, community-building activities and events, among others. Interviews were conducted in both Mandarin Chinese and English, and the English quotes in this essay were all translated by the authors, one of whom is a native speaker of Chinese. Our interlocutors include farmers, residents of farmlands we visited, agricultural policy makers in Taiwan, and more. Since Taiwanese farmers engage in activities and practices both in person and online (e.g., announcing events, exchanging how-to tips, and documenting and sharing farming activities in forums and social media such as Facebook), it was necessary to engage with subjects in their own terms, so we employed a set of digital ethnographic approaches $[16,52,77]$ to learn how experimental agricultural activities and interaction unfolds virtually and how farmers interface with others outside of the farming communities.

Interpretive Procedures: The research team conducted data analysis through a procedure known as explication de texte [35], or close reading, an analytical method originating in the humanities $[86,92]$. All three researchers involved in the analysis have training in the humanities and are experienced with this analytical practice. Broadly, the explication de texte proceeds as follows: initially the analyst seeks to build literacy with the main contents of the texts. This literacy, which might be characterized as knowledge that any other reader would share, gradually develops into sensitivity for the particular data set. Developing it, we examine our interlocutors' use of narrative structures, allusive resonances, connotation, diction, metaphor, etc. This phase follows an iterative, dialogic process, alternating between reading alone and reading together, and between reading theory and analyzing textual data-mutually informing one another until a picture emerges that seems to resonate with participant discourses and activities, our inquiry goals, theoretical resources, and our experiences.

Envisioning Alternatives: We used the ethnographies in a speculative way to help us envision alternative design futures. We took inspiration from long-term projects to observe how social entrepreneurs and other change-makers have configured their environments in pursuit of ecologically viable and restorative design (e.g. [66], [15]). We modelled our approach on what [70] refer to as "anticipatory design," a practice that uses "images [...] to creatively and speculatively imagine [...] a world not yet existing, but potentially worth pursuing” (p1395). As we analyzed the ethnographies, we sought to find in them "fragments" or "glimmers" of that world worth pursuing-even if those fragments were partial, flawed, or incomplete. The goal was not to predict the future, but rather to imaginatively "explore a radically better future without attempting to define it" ([6], p11). In our writeup, we occasionally use poetic language to try to evoke our experience of encountering these places and the stories we heard about them.

\section{WALKING THE GARDEN FORESTS}

Shengou Village (深溝村) is located in the rural Yuanshan township of Taiwan's breadbasket, Yilan County. In recent years, Yuanshan has become a site where experimental farmers seeking alternatives have come together with a shared vision amid commitments to pursuing sustainable futures in food production. A new generation of farmers is arriving in Shengou, many of whom are young, former city dwellers and professionals (e.g., lawyers, engineers, biologists, cultural anthropologists, media producers, designers, and architects) with advanced degrees. These smallholder farmers collectively express a desire to live in a different kind of human-land relationship: They practice and experiment with alternative farming techniques and principles to address ever-increasing deleterious environmental impacts; they seek to create symbiotic (as opposed to competitive) communities to improve civic and communal farming life; and they proactively cultivate affective relationships with small animals and insects often found in farmlands, for the betterment of a more resilient agricultural ecosystem.

We chose this research site to reflect different approaches to experimental farming, including organic farming, eco-friendly farming, small-scale farming, and farm hacking. We had two inquiry objectives: to understand 1) how contemporary ecological farming practices are developing alternatives to industrial agriculture, in hopes of exploring the potential transfer of such practices into HCI; 2) how these practices embody, exemplify and/or problematize strategies and tactics advocated by care ethics, posthumanist theory and ecofeminism. As is common in critical intellectual traditions, we move from descriptive accounts of our object of inquiry (to establish a basis of mutual understanding) towards increasingly interpretative ones (to develop our contribution). Thus, each of our vignettes is initially descriptive, while more interpretative claims are offered later in the essay.

\subsection{Problems of Scale}

Tucked away in Shengou village (深溝村), Land Dyke Family Farm (about 0.16 hectares of rice paddy) is a women's cooperative farm founded in 2012 by social activist Shawn Wu. The name Land Dyke was coined by American eco-feminists in the 1970s at the height of returning-to-the-land movement [Lin, 2017]. The six feminist queer farmers take inspiration from principles of collective cooperation to create a more community-based agriculture. They learned how to grow vegetables from 73-year-old Zhu Mei-chiao, a female veteran vegetable farmer, and decided to live and work together in Shengou village with rice cultivation as the primary crop and fruit and vegetables as supplement. Like other small-scale friendly farmers in Yuanshan township, Land Dyke is committed to ecofriendly farming and follows the sustainability principles of the Yilan Eco-friendly Smallholder Farmers' Alliance: it forbids pesticides, chemical fertilizers, and harming lives if they do not harm the crops, and the use of imported supplies [53]. Land Dyke, like many smallholder farmers in Yilan, does not own, but rather leases their farm plots.

Forbidding pesticides, of course, still leaves pests, and for the Land Dyke farmers, that would spell trouble: an infestation with tree-destroying scale insects threatened the orchard they were leasing. Land Dyke farmers noticed the presence of the insects in 
March of 2018 when the citrus trees started to bloom. Between March and June, members of Land Dyke did what they could with non-chemical control methods, such as wiping and washing affected leaves with lukewarm water and soap, flushing the infected bit of orchard with water, physically destroying ant nests on the trees, and spraying the infested plants with neem oil (biodegradable organic broad-spectrum pesticide). Nothing worked. The scale insects gained ground, in part because of the unusually high temperatures in the region, the delay of the 2018 monsoon season, and the insufficient quantity of ladybugs - the scale insects' natural predator.

The vulnerability of the crops combined with the economic precarity of the farmers all but guaranteed the outcome: Land Dyke was forced to spray pesticides to save the citrus. The use of pesticides in this case was not determined by an overarching industrial farming strategy, but more sadly was situated within an ethic of care. We see this in two ways. One is in the individual and situated relationship of the Land Dyke farmers and their trees; the farmers' emotional telling of the story is evidence. The other is the farmers' care for their neighbors' farms, that is, their sense of responsibility to keep the blight to themselves and not to let their problems harm their neighbors. Stated in Star and Ruhleder's theoretical language [98], the destruction of the crop was an event to be noticed, and the resulting "back-up mechanism"-spraying pesticides to help save a farming alliance largely defined by its shared commitment to avoid pesticides - emphasizes the infrastructural breakdown.

Environmental anthropologist Mathews introduces the idea of landscape structure, encouraging understanding of landscape as making "visible multiple throughscapes, landscape patterns that overlap and lie through each other, ... structured by particular morethan-human relations and proceed according to their own rhythms" ([75], p406). One may imagine the story told from the point of view of the scales, who discovered a proverbial land of milk and honey, or of otherwise harmless insects in the same area, who were killed en masse for being at the wrong place at the wrong time. In this case, the landscape of the orchard, with its monocrop vulnerable to scale insects, who are in turn vulnerable to pesticides, only supported one story, one pattern, one throughscape. The alternative is a practice of noticing more-than-human assemblages of people, plants, insects, and landscape is contingent, partial, tentative, at times speculative, and in back-and-forth movement: a story with "many beginnings and coexisting histories that give rise to multiple futures" [75]. It is to such a story that we now turn.

\subsection{Scratchy Weeds and Moonlit Ponds}

A moped ride away in Shengou Village, one finds Chen Xing-Yan (陳幸延) in one of his fields. Xing-Yan was born to a farming family, but left farming to pursue a degree and career in software engineering. Later, Xing-Yan decided to return to his roots, moving to Shengou Village and setting up his own farm. His engineering background shapes his farming, but not always in ways that one might predict. For example, he founded Open Hack Farm, a place where farmers and technologists devoted to sustainable agricultural innovation develop experiments with location-aware sensor systems. Likewise, he developed Farmer's Helper, a chatbot to alert farmers about severe weather, possible pest attacks, and to make planting recommendations.

One might expect his farm to display the structured rationality of his disciplinary training. But his plots don't look like farms at all: there are no tidy rows of similar plants, wooden scaffolds, bug screens, walkways, or other visual signs of agriculture. Standing at the side of the road, we were confronted with an apparently haphazard amalgam of weeds, mud, insects, and crops. We scanned left and right before asking Xing-Yan where his farm was. Laughing, he said it was right in front of us. We took a last look at our clean shoes before taking a step of faith from the asphalt. Xing-Yan characterizes his farms as garden forests (chai-yuan-seng-ling: 菜園 森林). That is, each farm is a small but whole ecosystem. Instead of seeing unplanted vegetation as weeds, he sees them as companions to his rice [71]. They are there to serve a purpose: they cover the soil and maintain its moisture, offer shelter to critters in his field, help compete against other invasive weeds and provide sugar glucose through photosynthesis to feed the soil's microorganisms. That's a lot of work, he observes, and he'd rather let them do it than to do it himself.

Xing-Yan's blend of software engineering and agricultural labor can be subtle and hard to see on his farm, but in other cases it is much more straightforward. Each year in the spring, the fertile fields of Yilan come back to life for a new year. As the soil warms up and the spring rains fall, seeds sprout and critters emerge. Marking this event is an annual agricultural ritual known as jingzhe (驚 蟄), signifying the new season's return of insects and small critters. Among those critters are golden treasure snails, which every spring awaken from their winter hibernation seeking to fill their bellies with tender rice seedlings. Because they reproduce at a baffling speed, they can quickly overwhelm rice paddies [104], leading to one of the area's time-honored traditions among eco-farmers. Guided by the traditional Chinese lunar calendar, usually on a cool March midnight, the rice farmers in Yilan come out to confront tens of thousands of hungry golden treasure snails. Standing up to their ankles in the chill water, the farmers bend over to pick the snails up by hand, depositing them in buckets.

The back-breaking labor involved in snail harvesting gives a strong incentive to use pesticides. But the snails are not the only living creatures in the rice paddies, which contain shrimp, waterfowl, water scorpions, mole crickets, fish, paddy frogs, toads, clams and an even wider assortment of microorganisms. Pesticides used against snails would kill most of these, utterly changing the ecology, and requiring an assemblage of "backup mechanisms" to compensate. Moreover, Xing-Yan believes that these organisms together can do a much better job farming than any farmers.

Balancing the needs to decrease the physical labor and pain required to deal ethically with the snails and allow non-human "farmers" to work, Xing-Yan recently collaborated with other rice paddy farmers and open-source enthusiasts to develop an automated, time-controlled picking system for golden treasure snails (Figure 1), using 3D-printed parts and hardware readily available in Taiwan. The system works by attracting the snails to the circular apparatus first. A slow-moving gate gently rotates to contain them. Once confined, they can be easily carried away.

From the Open Hack Farm, which resembles an outdoor 3D printer beside a barn, to his visually chaotic garden forests, to 


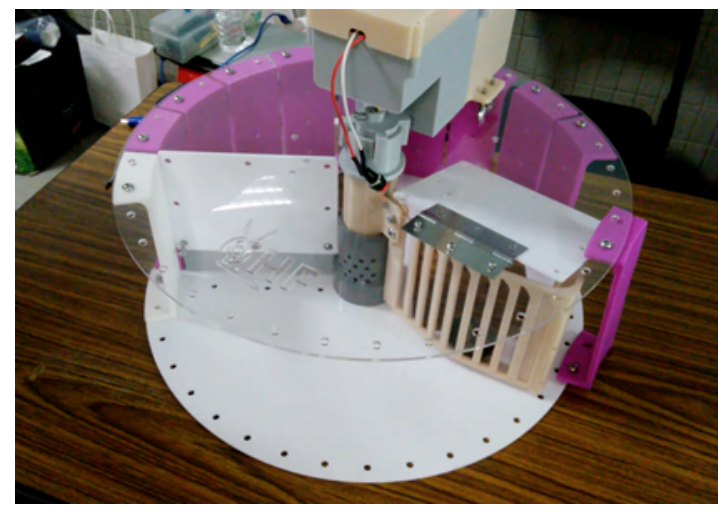

Figure 1: Automated Snail Collector led by Xin-Yan Chen

his brightly-hued DIY snail collector, Xing-Yan exhibits variations of what it might look like when an accomplished engineer subordinates himself to a natural ecosystem. Here, he supports the overall natural system much as fellow constituents-weeds, insects, microbes-all do their parts, working sweaty shoulder to diaphanous wing. Xing-Yan was animated when he shared with us his principle of "allowing all living creatures and organisms to carry out their work naturally and independently." He believes the ecology is already in place, and his job as a farmer is not to change or to dominate it, but simply to "facilitate" what nature is already doing. Xing-Yan's efforts demonstrate that even sophisticated human disciplinary practices can be subordinate to natural and otherwise non-human systems, while remaining both efficacious and professionally fulfilling.

\subsection{Spots on our Apples, the Birds and the Bees}

Nearby, in a farm plot separate from the scale-infested fruit orchard, Land Dyke farmers also experiment. Farmer Joelle Chevrier (also known as 雪青) is an American who was studying Chinese literature in Taipei when she joined the farm in 2015. Joelle is one of the "half farmers, half X," who extends her income doing translation work.

In 2019, Joelle celebrated over social media the success of her experiment in what she referred to as abandoned farming (葉作 農法). Her idea in the spring was to plant in such a way that the farm self-regulates and ultimately produces crops without further human intervention; hence, the farmers "abandon" their farms. The key, she explains, is in "identifying crops that are strong enough to compete with invasive weeds in the fields to survive extreme heat and humidity in the summer in Taiwan with little care from farmers." This strategy fits in this climate, because Yilan's summer fields are treacherous as a result of fast-growing weeds, insects, and other organisms.

Later that summer, Joelle returned to her "abandoned" fields to discover, with a combination of surprise and triumph, that under the weeds and grass buzzing with mosquitos, her farm was filled with pumpkins, eggplants, water spinach, and a "small, ugly, insectbitten, yet nonetheless completely edible" loofah. Her practice here is akin to what Tsing and her colleagues [108] refer to as "feral proliferations"-the "mixings of insides and outsides" of human structures, such as farms. Instead of attempting to minimize, if not outright obliterate, these feral proliferations, Joelle has engaged in the kind of experiment that reframes relationships among human farmer, crop, and feral life.

As with Xing-Yan's garden forest, Joelle's abandoned farm embodies an alternative to the conventional monocrop farm, with more resistance to monocrop farms' vulnerabilities -e.g., systematic crop destruction because of insects, disease, and so on. The farms accordingly lose the geometry that many of us associate with agriculture: their square plots, irrigation circles, replications of neat rows. Joelle makes clear that her produce loses some of its traditional aesthetics-her produce is ugly, though "still edible." Yet the shapely aesthetics of farms and produce come with a heavy price. As Tsing et al. [108] write, conventional farms are simplified into a "modular" system (e.g., plots, rows) the better to facilitate management. But what is managed is not merely crops, soil, and insects, but also the labor required to make them productive. They argue,

Contemporary plantations .... carry histories of slavery and the displacement of indigenous communities. This "modular" simplification has spread around the world together with human coercion as plantation labor; this regimentation of human and nonhuman life must be thought together. Plantations attempt to reduce the number of living things in an area to just one kind; everything but that which is required for the reproduction of the economic product should be eliminated. ([108], p189)

When Xing-Yan and Joelle reconfigure the physical arrangement of their farm plots, they also reconfigure the labor of who does what. Weeds, bugs, and microbes start to do farming tasks that otherwise would have been done by manual laborers, machines, and chemicals. And tasks to optimize the farm and produce conventional agricultural aesthetics are not done at all. Xing-Yan explains, "the foundation of farming lays in the soil, and the healthiness of the crops have a lot to do with the microorganisms within it, so the most important task for me is to cultivate soil with compost... if you provide a good cultivation environment the crops naturally will grow well. It's not even my task to worry about the pests."

Xing-Yan and Joelle's practice share another feature: both name their experiments using evocative metaphors: "garden forest" and "abandoned farming." These metaphors not only capture the central governing principle of each farm but evoke images with alternative aesthetics. A "garden forest" does not conjure neat rows and paths and monocrops, but something dense, heterogenous, teeming with life, and yet serene. Likewise, an "abandoned farm" suggests human habitation that is overgrown, planted but gone to seed, a link to a past literally overwhelmed by the urgency of life. It yields food from the "primary infrastructures" of soil without resorting to the "backup mechanisms" of hazardous chemicals and human physical labor. The metaphors intervene in our imagination, proposing alternative images of food production practices that are enticing-perhaps as enticing as the spotless apple of conventional agriculture. 


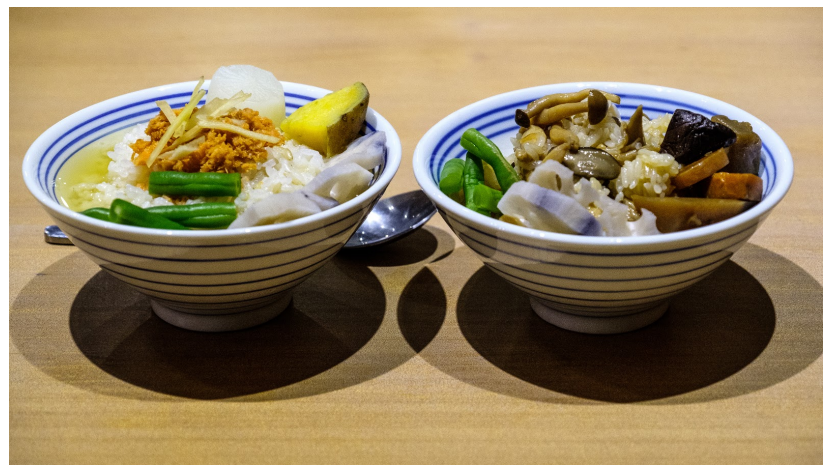

Figure 2: Mei-Hong's home-style cooking

\subsection{A Community Bonded with Sticky Rice}

Throughout their experiments, whether they end in failure, success, or something in between, the labor of the farmers of Shengou Village is infused with intimacy. Intimacy here means more than the regular acquaintance that arises out of daily work with plants, soil, and fauna. It is more than an intellectual understanding of the effects of nonhumans living in the rice paddies and fruit orchard, from waterfowl, golden treasure snails, to pesticides and other forms of toxicity. Intimacy is a shared way of being and a feeling of recognition, of mutuality, a sense that another is "of one's flesh" [23]. Pursuing such intimacy is a life purpose of longtime resident of Shengou Village Mei-Hong Zhu, owner, manager, head chef, and server at Mei-Hong Diner. With no fixed menu, she offers homestyle dishes made with locally grown organic produce. She tries to create a sense of "eating at Mei-Hong's home."

Visiting her diner in late fall of 2017, one walks into its single room adorned with wood, bricks, and tatami sitting. The restaurant's commitment to environmentalism is evident: its restroom features a box of peat, later to be used as fertilizer, rather than a conventional toilet with running water. Back in the seating room, a blackboard lists the day's specials, indicating where the ingredients were sourced. Cups of steaming purple sticky rice tea, hand-roasted by Mei-Hong, are ready. She serves two dishes-one of rice and local vegetables, the other Mei-Hong's reinterpretation of Japanese Ochazuke, a dish in which hot tea is poured over cooked rice topped with few other simple ingredients (Figure 2).

Mei-Hong tells how she and her husband, Chin-Sung Lai, came be regarded as the core of the small farmer collective in Shengou Village. Chin-Sung, like Xing-Yan, pursued advanced education in engineering, in his case in Japan, but, in 2004, the couple returned to Yilan. Mei-Hong leased rice paddies from her relatives to experiment in eco-farming approaches. Witnessing other Yilan farm holders moving to the city, Mei-Hong and Chin-Sung saw an opportunity to bring more eco-friendly farmers to Yilan. Relying neither on kinship nor commerce, the couple initiated a project Two Hundred Hectares (兩佰甲), which leases rice paddies to farmers if they promise not use chemicals when caring for the land. The couple then used the program to teach these farmers everything from organic wet rice farming to eco-friendly ways to collect and re-move golden treasure snails.
The couple were also instrumental in developing a parallel initiative: The GuDong Club or Grain Shareholder Club (款東樂部). Each shareholder contributes financially every year, based on household rice consumption needs, to pay for all farming tasks in Shengou Village, from renting farm lands, to planting, weeding, harvesting, rice-milling, transportation and storage of rice, and fallow management. Shareholders collaboratively determine how much to plant and set rice prices each year. They also share farming-related risks such as weather and pest damage, as a bartered insurance plan. In Shengou Village, many of the $300+$ Club members regularly participate in farming activities, and some even started farming on their own years later.

The two initiatives - Two Hundred Hectares and The Grain Shareholder Club - replaced a failing conventional agricultural area with a thriving eco-farming community. The economic decline of farmers in Yilan mirrors that of many other agricultural communities throughout the world. As the profession increasingly became seen as neither economically viable nor desirable to work in, children of family farmers moved to the city to pursue different careers. Rich urbanites bought up the emptying family farmhouses as vacation homes, while the ancestral farms, no longer operating, became bucolic scenery for the vacationers. Such trends impact food sovereignty and the capacity for neighborhoods (and, indeed, whole countries) to provide healthy, locally-sourced sustenance.

In such a context, Mei-Hong and Chin-Sung help replace the family farm structure with a non-kin/odd-kin format, which entails "surviving-together and becoming together through forging morethan-human alliances" [103]. Cementing these social bonds is not kinship, but rather working together on land they do not even own and agreeing to conduct that work in a certain way: avoiding chemicals and nurturing multispecies collaborations with insects, small critters, and even fungi in the rice paddy ecology. In the words of cultural anthropologist and Land Dyke farmer Yan-Ling Tsai, such multispecies co-survival "harbors some hope for a different aligned politics and a more inclusive and liveable Anthropocene" [103].

Mei-Hong explains how the couple helps new farmers acclimate into working and living in Shengou Village:

When an aspiring famer arrives in Shengou, my husband Chin-Sung would help her/him find the land to farm, and I find a house for her/him to live... when something comes up, we are always there to offer help. Over time, people just show up at our door regardless whether they need anything from us .... We don't subscribe to the idea of "minding one's own business" here.... We are here to live, to lead a good and happy life... part of it is to make it possible for others to get going fast and be successful in however they define the success to be... I like the newcomers and want them to stay in the village, to feel the energy and hope like we do, so I help them. . . to me, the important thing is not so much about how to make a living here; it is whether one has the desire to live here that matters the most.

Mei-Hong creates connections and social infrastructure that make it possible for a community of eco-friendly farmers to thrive 
in Shengou, where the food she prepares plays a role in sustaining these new families. She explains,

One day the kids who grow up in Shengou might leave the village for education or work, but I hope they remember soy sauce in the summer and smoked meat in the winter when they are away, that the smell and taste of my food will for-ever stay with them and will remind them of Shengou, and become a source of positive energy to carry them through hard times.

Proust's account of a madeleine cake [88] exemplifies the idea that the earliest tastes of childhood remain with us across our lives. We are anchored in these early memories; all that is comfortable and right in the world is bound up with and activated by these smells and tastes. The family farm once comprised an economic system, social structure, ideology, set of places and practices, and intimate memories of food and family. As that system collapses in Yilan, Mei-Hong serves up an alternative, one farmer, one plot, and one bowl at a time.

Anthropologist Gray conducted an ethnography of sheep farmers in Scotland, in which he sought to understand the relations among humans, sheep, and land. He introduces a concept called emplacement, which refers to the "relational configuration of humans, animals, and land in which shepherds and sheep-in their own way according to their particular abilities-create an embodied sense of place through mutually attending to each other's motivated movement over the landscape" [42]. Emplacement entails a relationship of intimacy, where land, farmers and sheep mutually shape and define each other, a relationship so significant that conventional structures of ownership and economic production barely reach it. We see an analogue in Mei-Hong's efforts to build and sustain a community of new eco-farmers in Shengou. These, too, constitute acts of emplacement that bind together non-kin/odd-kin farmers; their wet and snail-filled paddies, their "abandoned farms" and "garden forests"; the weedy biosphere under the waxing and waning moon. In Shengou Village, economic viability is an important outcome, but it is not an end in itself. The end is "whether one has the desire to live here."

\section{GLIMPSES OF "HERE"}

We argued earlier in the essay that the kinds of experiments that we study often embody the values, strategies, and tactics of posthumanism and care ethics, providing glimpses into a future where they could be more commonplace or operating at a greater scale. Using cases of farming from Taiwan, we have shown how the prioritization of (more-than-human) respect, intimacy, and interdependence has changed practice. We will now consider three ideas derived from this research that might contribute to efforts to transition HCI and design away from anthropocentric functionalism towards a more care-oriented discipline. The three ideas are as follows: pursuing "wanting to live here" via place-based common resources, the pursuit of a posthuman engineering that is aware of IT's participation in biosystems, and the prototyping of land-based care collectives. We do not mean to propose these ideas as "right" or sufficient. Rather, we wish "to engage critically and with curiosity" [108] in considering them as worlding [46]. Following Shaowen
Bardzell [6], we engage them as "utopian glimmers," that is, fleeting and fragmented images of what HCI and design might look like.

\subsection{Wanting to Live Here}

Shengou farmers are productive, in the sense that they do produce food and knowledge, yet that is not what shapes their shared identity. It is a whole way of being: an economic vision, an ideology, a set of formal and informal contracts, shared practices of making and production, a kind of social belonging, a collection of symbols and rituals, and an experienced sense of collocation. Visiting, the village feels as dense, heterogeneous, and fertile as Xing-Yan's garden; it offers for the farmers a deeply satisfying way to live, as confirmed by Mei-Hong: "to me, the important thing is not so much about how to make a living here; it is whether one has the desire to live here that matters the most." In contrast, the agrarian and industrial revolutions produced a focus on generating economic wealth and societies are increasingly realizing that it did so at the expense of our desire to live "here"-whether "here" refers to specific localities, including polluted cities or factories requiring harsh and repetitive labor, or the planet itself, with its colossal storms, floods, and wildfires, its pandemics, and its vulnerability in the face of providing even the basics of life, including food and safe water.

We are not suggesting a reversion back to the days before the industrial revolution. Indeed, the crop farming in process at that time already shared many of the commitments that we are hoping to change [78,94]. Rather, we are seeing in Mei-Hong an entire system of being with the land. If $\mathrm{HCI}$ is to move away from anthropocentric functionalism toward care; if it is to look beyond the efficiency of human-machine relationships to pursue values of respect, interconnectedness, concrete relations that are infused with meaning for all parties (on whatever terms), and ongoing acts of care-then "but is it economically productive?" cannot be the bottom-line question. Perhaps "but do we want to live here?" could be. It remains selfcentered as an approach, but invokes the concept of "emplacement," introduced above. In doing so, it reinstates judgment, sensation and desire into our formulae. It allows us to continue to discuss who the 'we' of the question may be: all of humanity or all living creatures? Emplacement, as a making of place through the intimacy of developing and enduring relations among all-human and nonhuman-who share land, becomes not just an inevitable process of entanglement through proximity, but a deliberate strategy that involves engagement with land, diversification, local management and ongoing relation-building.

In such a place, livelihood remains important. As noted earlier, many of the Shengou farmers have separate employment in other professions and we are not holding this up as a currently viable independent financial model in competition with other farming systems. Instead we are demonstrating a different economic approach: care is manifested within the farming structure, in economic structures that both diminish risk and support life, including equivalents to insurance, access to local and urban markets, and diverse supports for all aspects of farming practices and cycles. Shengou's innovation is not that it has rejected contemporary forms of exchange, such as insurance. It is rather that it has reconfigured some of those exchanges and thereby supplemented them with what Light and Miskelly call "relational assets" [65,66]. 
Relational assets are the emergent capacities that come with the accumulation of multiple collaborative care intitiatives within a locale. They are part of a virtuous spiral that promotes agency and pro-social values. They are place-based rather than individual; beneficial to everyone within a neighborhood to some degree; and emerge through the accumulation of processes, initiatives and tools for sharing resources, developed through local collaborations and the exercise of goodwill. The Two Hundred Hectares and GuDong Club support the development of relational assets, embodying both formal and goodwill exchanges. That is, they feature arrangements that formally recognize shareholder rights and also exchanges that do not entail immediate reciprocity, expressed in Mei-Hong's "we are always there to offer help" not asking for anything in return because "I like newcomers and want them to stay in the village, to feel the energy and hope like we do." Nonetheless, tourism, property leasing, rail- and highway-based transport infrastructure, import/export, university connections, high speed internet, podcasts, and so on, tie Shengou to the city and indeed the rest of Asia. While this may beg the question of what happens if every village adopted these same tactics, it is not glib to say we are so far from this point that this is the least of our concerns. Instead we point to these ways of thinking as transitionary and transformative. The point is that the economic infrastructure is a resource in service of a living place, not the other way around.

Designing to cultivate relational assets has several benefits. One is that its location-based nature puts an emphasis on land use and the importance of place, which is often abstracted out of system and platform design. Another is that it extends to non-human actors, helping to undercut the anthropocentrism of most design. A third is that they are capacity-building, generating their own energy once set in motion. Finally, relational assets should not be unfamiliar to HCI: in some ways, they can be read as a subspecies of "boundary objects," whose implications for communities of practice as well as communities of interest have been developed into mature theoretical perspectives in the HCI research literature. To those communities, we might add a third: communities of flourishing.

\subsection{From Posthuman Engineering to Biotechnical Interactions}

Shengou farmers have not only reconfigured social structures, but also how we might understand the engineering profession, as we found in Xing-Yan's personal history. The apparently radical change in his career from urban software engineer to rural farmer masks the underlying continuities between his chosen employments. It is likely, for example, that his childhood experiences as a farmer contributed to his interest in studying engineering. And coming back full circle decades later, his engineering skills were visible throughout his farming. He developed automated and semi-automated systems to support a systemic and ongoing knowledge about his farms (e.g., soil health, microbiological processes, temperature). He used a free/libre open source methodology to develop and replicate both the systems and their outputs to local farmers. He was well aware of inefficiencies and the actors-human and non-humanbest positioned to address them, and he optimized both human and non-human labor configurations to get agricultural work done, augmenting human intelligence (e.g., with networks of sensors and data visualizations) and human labor (e.g., with automated systems, such as the snail collector, and by allowing the natural world to manage itself so humans need not). However, he never prioritized efficiency as an end in itself. (Though he definitely prioritizes human crops at the expense of feeding snails.)

Xing-Yan never stopped engineering. Today, he continues to build systems. But instead of using his engineering abilities to dominate and control his environment-as in conventional industrial agriculture-he subordinates his engineering ability to the governance of nature. As nature prefers resilient and heterogeneous biosystems, Xing-Yan uses his advanced training to do his part to support the flourishing of such biosystems. In other words, Xing-Yan's success as a farmer is not contingent on his turning his back on engineering; he seems successful in large part because of his engineering ability. Returning to the dilemma with which we opened the essay-can HCI, a discipline that contributes to environmental crisis thanks to its anthropocentric functionalism, bring about global change toward nurturing life?-we suggest that Xing-Yan's career proves it is at least possible. We find hope in this, because it gestures towards the possibility of addressing environmental crisis by moving forward, rather than by disavowing our present and attempting to return to a romanticized past. Designers can still design; HCI can still make things. In rethinking what we design, we do not negate design, but consider where we put our efforts (e.g., [62]). Xing-Yan's story shows a way that any of us could realign our thinking beyond control methodologies [73].

We could also view Xing-Yan by taking a historical perspective. The three waves or paradigms of HCI [17,47] respectively focused on systems in support of (individual) human-machine interactions, broadening into organizational and collaborative systems in the workplace, and then broadening further to the entire human lifeworld. Xing-Yan's approach broadens further to biosystems-open source systems featuring biomimicry and biomeasurements, systems that support biological health and processes. With such a perspective, $\mathrm{HCI}$-as it once shifted from one-person, one-terminal systems to sociotechnical systems-today might now shift again to shape the emergence of what we think of as biotechnical interactions.

\subsection{Prototyping care collectives}

We started this journey in the scale-infested orchard, where monocropping and its vulnerabilities overwhelmed the farmers when they attempted to remove the orchard's dependency on pesticides. Yet the Land Dyke farmers were trying to prototype a different kind of farming, a prototype that happened, in this case, to fail. Notably, they marked this infrastructural breakdown as a kind of event, thanks to the ways they reported the breakdown to the community, making it accessible for learning. Other prototypes, such as their "abandoned farms" were more successful-in 2019, at least. Prototyping alternative ways of being must forever be reinvented, tried and tried again. Both successes and failures, however, are of a piece-or, more properly, of a place. That is, experiments such as the ones summarized above are not only enacted by the specific individuals behind them, but by a community that has come together, 
and configured itself, to support such experiments. Its configurations include economic, intellectual, practical, and geographical dimensions, and collectively they "emplace" the prototypes. That is, just as the humans, sheep, and craggy hills of Scotland interrelate, so do the farmers, critters, and plots of Shengou; their prototypes are as emplaced as the rich soil itself, forming a "relational asset" $[65,66]$ that makes it safer to try out new relations. These experiments are not prototypes that can be scaled out to new pastures; they are prototypical in that they never reach a final version. Only the ideas and the culture of risk-taking can be proliferated across soils and continents as part of learning how to live in greater balance.

What we are drawing attention to is that the farmers' put themselves into a position-economically and intellectually-to prototype. It is this that interests us, as much as any outcomes of the prototypes. Part of the experimentation is economic-which crops grow sufficiently well in neglect; part is social-how the routines of farming might be modified so that some of the harshest labor is automated; part is ecological-how natural processes are supported with minimum intervention. In fact, Shengou Village today bears some of the hallmarks of a traditional farming village. Such a village might be read as a cogent composition of social relations, practical knowledge, systems of formal and in-formal exchange, a view of the good life, a stable political economy (e.g., land ownership, markets), rituals, forms of intimacy-all tied up in the tastes and smells of harvests, lunar holidays, and thousands of breakfasts. Mei-Hong convincingly shows that rethinking land usage with a little vision supports the coherence of behaviors, beliefs, rituals, attitudes, and knowledge practices that make kin without depending on the traditional atomic family unit-i.e., making kith instead [46]. The emplacement of farmers, non-human life, value (and other social) systems, farm plots, and prototypes provides stability, a platform that transcends the success of any given prototype. Shengou has achieved a "situated-together-ness" that constitutes a community and also a platform [66] for prototyping alternative ways of living with/in/on the land. Knowledge outcomes can be very localized and practical-e.g., daily soil conditions in Shengou-to hypotheses and theories of new forms of farming (e.g., the vision of Shengou).

While resource use is almost always a consideration of $\mathrm{HCI}$ research and practice, we encourage a heightened focus on land usage and the way that place can impact sociotechnical relations. It is land usage that enables (or preempts) emplacement. We therefore encourage HCI researchers and practitioners to pursue IT initiatives that contribute to, rather than dilute or disrupt, emplacement. Emplacement can be understood as an alternative to anthropocentric functionalism; it is a situated-together-ness, a functional and selfsustaining system comprising human and non-human actors and the environments they co-inhabit, and a kind of intimacy derived therein. At a time when networked platforms are disrupting informal economies and accelerating a movement from place-oriented to place-agnostic services [66], this emphasis on situation is not merely a matter of context, but a matter of care, of scale and, ultimately, of survival. It asks of HCI to consider how management of resources stays accessible, how diversification is incorporated in strategy and how people can experiment and learn as part of their day-to-day-all being important parts of being able to flourish that the infrastructure of monolithic IT systems has a tendency to close down.

\section{CONCLUSION}

We opened the essay wondering how a discipline that puts humantechnology relations at the center of its practice might be positioned to contribute to the transformations needed to address looming climate crisis. We did so in the context that the concern for humantechnology relations has furthered paradigms of ever-increasing production via value extraction. Along with others, within and outside of HCI and design, we take a perspective based on a deep commitment to interdependence that challenges anthropocentrism and the rationalist epistemologies and practices driving it $[46,108]$. Again, critiques of rationalism in HCI are hardly new, yet mainstream HCI, in spite of a number of serious efforts, is not where many in the sustainable HCI community believes it needs to be. This reflects the difficulty of the goal-to reposition a field tied to economic growth agendas. What becomes clear in readings from ecofeminism $[8,56,39,111,112]$ and care ethics $[5,11,62,64,89,90]$ is that the ethos of our whole system has to change if we are to achieve sustainable futures.

With these case studies, we hold a mirror to HCI from a different field, that of agriculture, and attempt two related tasks: to reconsider basic principles of making and production in the light of these farming practices and to offer a vision of how we, as practitioners, might change ourselves to support the transition to new principles and new ways of designing in the world. We do this by pursuing fragments and glimmers of a different way of socially organizing places where food is grown, and lives, including but not limited to human, are nurtured. In line with current thinking in SCHI [12,67,80,13,44,58,81,95,105], this is not just to change superficial design components, nor even an intellectual challenge to the underpinning philosophy of the field, but rather an attempt to imagine and to implement a whole new system: a holistic composition of philosophy, practice, material living, place, and ideology. It is to speak of the socio-technical infrastructure of new relations, but also of making the change. As our first example shows, it takes more than a commitment not to use pesticide; it takes a rethinking of crops, crop management and expectations of productivity. The alternative, the tweaks, merely resulted eventually in a threat to the whole crop and that of the neighbors', and the absolute compromise of a return to spraying. This, in itself, is a metaphor for where we stand as makers. The system needs re-designing, not just our responses to its effects.

None of these changes requires swearing off technology or developing a nostalgic yearning for a pre-industrial economy. Neither do they require rejecting humans' desire to make things, or designers' desire to design things. We offer here a much more positive take-home: if we argue that design as a discipline is responsible for revealing and delivering desiderata [82], then it follows that our conception of a re-designed design should still do so. What if this function of design-to reveal and to deliver desiderata-was directed at biological flourishing, rather than economic growth? What new forms of life and economy would fall out? How might we "like to live here"? We saw how Xing-Yan, Joelle, and Mei-Hong designed new farming practices and infrastructures, giving them 
metaphorical names that implied something more aesthetic-a vision of a good life, of a way of being in the world and relating to others. Of course, this begs the question of desirable to whom? Recent movements toward justice and sustainable lifestyles suggest that a majority across the world is seeking a "new normal" that acknowledges what is wrong with current exploitative systems.

However, if we attend with this level of granularity to our cases' achievements, it becomes obvious that this form of engagement with land and with other living beings is not possible to scale and therefore cannot offer a single alternative to business as usual. There is much in the mood and concepts that is portable, and, we argue, the question: "do we want to live here?" could guide future development. But in prototyping new arrangements, the search for scalable definitive answers is another practice that we need to reconsider. Local solutions that respond to local conditions will be more important than the homogeneity underpinning mass scale operations, from agriculture's monocrops to architecture's modular building components to the data preparation upon which artificial intelligence depends. This is why we say that the prototyping is ongoing.

Throughout the research in Shengou, we observed a small scale yet comprehensive restructuring of society. Exchanges of goods, money, and labor are still present, but they are not oriented towards wealth creation or "getting ahead"; instead, they are oriented at sustaining a way of life perceived as desirable-sustainable both in terms of meeting people's across the seasons and over the years, and also at meeting wants: for fellowship, flavorful home cooking, a dynamic and physical relationship with the land. Traditional professional roles, including entrepreneurs, biologists, engineers, teachers, and even media personalities are also present, but again, these roles are often structured in ways other than what one might find elsewhere: engineering subordinated to natural processes, rather than controlling them; entrepreneurship where the primary vision is not to generate revenue but to be able to eat in the kind of restaurant you believe should be on the corner. Common agricultural challenges, such as pests and bad weather, are also manifest in Shengou, but the attitudes and strategies used to address them have likewise been reconfigured to fit the community ethos-socially and chemically. Although Xingyan's plot's appearance was such that we initially didn't even realize that it was a farm plot, nonetheless it actually was a farm plot. To be sure, the relationships among food producing plants, weeds, soil health, and human and non-human labor alike had been redistributed, but like any other farm, it was intentionally designed to produce food, it was maintained, it had a logical and visual structure that fit its purpose. From one perspective, everything changed, but from another, nothing changed.

If our interlocutors in Taiwan provide glimmers of an alternative future, then we see that design might benefit from a similar restructuring. This requires more than critiques of rationalism or appeals to posthumanist and/or care theory, important first steps though they may be. And it would entail some rejections as well: it would reject Simon's separation of the "artificial" and "natural" worlds [96]; it would refuse to use or to produce the toxic; it would treat modular simplifications-from factories to plantations-with suspicion. It would question whether it is extracting from-as opposed to sustaining-people and environments. It would depend on, rather than attempt to replace or simulate, natural processes and nonhuman actors. It would be rooted in place, and specifically land, and it would respond to the needs of local ecologies, revering life rather than ideas of technological progress. This would force questions as to how global networks stay locally relevant (or even if they have a future in a recognizable form); what practices and tools resist extractivism in ICT production and deployment; how minority cultures and ways of knowing might be supported better; and how systems can promote life-affirming rather than humiliating or distracting [67] outcomes.

But it could also entail, we believe, preservation, that is, keeping but restructuring much of what design already is. Design is already powerful in making symbols for change (e.g., the Extinction Rebellion hourglass: [113]). It is already being the change it wants to see (e.g. solidarity [109], Transition Towns [107]). It is effective at revealing desires that people didn't know they had [82]. Each of these qualities is worth preserving. Further, as Alexander [18] reminds us, design processes can unfold in nature-like ways-that is, as situated in and reproducing what he calls "living structures"or they can be created in non-living ways: "processes which work against the existing life of a place, which fragment it, ignore it, cut across it, do damage" ([18], p5). Instead of cutting across existing life, he continues, we need a conception of the design "process itself as a budding, as unfolding through which the future grows from the present in a way that is dominated by the goodness of the moment" ([18], p12). And the goodness of the moment is "guided by the minute-to-minute necessity of caring, dynamically, for the feelings and well-being of another" ([18], p9). This is not sentimentality, but a recognition of the necessity for life to create new life, not merely to extract from existing life; to act otherwise is to defuture.

Shengou is a place where one might like to live, because, following Alexander's logic, what is good about the village has emerged out of the goodness of the village. This requires us to consider how we regard place, not just as a backdrop for our work, nor merely as a rich socio-semantic context, but as providing the physical materials and sites of production, consumption, and disposal in designingnot "a place to live" but "a living place." HCI has encountered "place" in many contexts, but often as a shell for innovation not a partner in material craft [62]. Here we draw attention to the extreme situatedness of what has been achieved in Shengou. For example, the socially shared dinners enjoyed in the restaurant are satisfying not only because the food tastes good or reminds one of home, but because the food is of home: it made here by the same hands now used to consume it, wholesomely done in accordance with cultural values, practices, and tastes of Shengou. As Light and Miskelly argue in the context of technology [66], there are social and ecological benefits to keeping the skills and means of production, as well as the product, local. In our parallel examination of how people have challenged anthropocentric functionalism in the agricultural sector, we note similar matters of situatedness and scale. Sitting at the table, one can feel the food not only in digesting it, in that feeling of satiety, but in the relaxing of the sore muscles that helped to produce it. This description sounds in some ways idyllic, but it is not a fantasy utopia; its sustained existence and growth offers proof that agriculture-and by extension, other disciplines that shape environments, such as $\mathrm{HCI}$ and design-can be a living structure-a "design process itself as a budding." 


\section{ACKNOWLEDGMENTS}

We gratefully acknowledge the support of National Science Foundation grants \#1908135 and \#1900722, our interlocutors for their time and insights, as well as colleagues and peer reviewers who have helped us to improve this work.

\section{REFERENCES}

[1] Liam Bannon and Susanne Bødker. 1991. Beyond the interface: Encountering artifacts in use. In J.M. Carroll, ed., Designing Interaction: Psychology at the User Interface. Cambridge: Cambridge University Press.

[2] Jeffrey Bardzell and Shaowen Bardzell. 2013. What is "critical" about critical design? In Proceedings of the SIGCHI Conference on Human Factors in Computing Systems (CHI '13). Association for Computing Machinery, New York, NY, USA, 3297-3306.

[3] Jeffrey Bardzell and Shaowen Bardzell. Humanistic HCI. Synthesis Lectures on Human-Centered Informatics [Series editor: John M. Carroll]. Morgan \& Claypool Publishers, 2015.

[4] Jeffrey Bardzell, Shaowen Bardzell, Lone Hansen (2015). Immodest proposals: Research through design and knowledge. Proc. of CHI2015. ACM: New York.

[5] Shaowen Bardzell. (2018). Through the "Cracks and Fissures" in the Smart Home to Ubiquitous Utopia. In Bardzell, J., Bardzell, S., and Blythe, M. (eds.). Critical Theory and Interaction Design. MIT Press.

[6] Shaowen Bardzell (2018). Utopias of Participation: Feminism, Design, and the Futures. ACM Transactions on Computer-Human Interaction (TOCHI). ACM.

[7] Shaowen Bardzell, Jeffrey Bardzell, and Sarah Ng. 2017. Supporting Cultures of Making: Technology, Policy, Visions, and Myths. Proceedings of the $2017 \mathrm{CHI}$ Conference on Human Factors in Computing Systems. Association for Computing Machinery, New York, NY, USA, 6523-6535. DOI: https://doi.org/10.1145/ 3025453.3025975 .

[8] Shaowen Bardzell, Daniela K. Rosner, and Jeffrey Bardzell. 2012. Crafting quality in design: integrity, creativity, and public sensibility. In Proceedings of the Designing Interactive Systems Conference (DIS '12). Association for Computing Machinery, New York, NY, USA, 11-20. DOI: https://doi.org/10.1145/2317956.2317959.

[9] Shaowen Bardzell and Eli Blevis. (2010). The Lens of Feminist HCI in the Context of Sustainable Interaction Design. Interactions magazine. ACM: New York.

[10] Lindsay Barbieri, Sonya Ahamed, and Sam Bliss. 2019. Farming Within Limits. Interactions, SEPTEMBER-OCTOBER 2019, 70-73.

[11] Seyla Benhabib. (1992) Situating the Self: Gender, Community, and Postmodernism in Contemporary Ethics. New York: Routledge.

[12] Eli Blevis. 2007. Sustainable interaction design: invention \& disposal, renewal \& reuse. Proceedings of the SIGCHI conference on Human factors in computing systems. ACM, 503-512.

[13] Eli Blevis. 2018. Seeing What Is and What Can Be: On Sustainability, Respect for Work, and Design for Respect. In Proceedings of the 2018 CHI Conference on Human Factors in Computing Systems - CHI '18, 1-14.

[14] Mark A. Blythe, Kees Overbeeke, Andrew Monk, and Peter C. Wright, eds. 2003. Funology: From Usability to Enjoyment. Springer.

[15] Joanna Boehnert. 2018. Design, Ecology, Politics: Towards the Ecocene, Bloomsbury Academic.

[16] Tom Boellstorf, Bonnie Nardi, Celia Pearce, and T.L. Taylor. 2012. Ethnography and Virtual Worlds: A Handbook of Method. Princeton University Press.

[17] Susanne Bødker. 2006. When second wave HCI meets third wave challenges. Proceedings of the 4th Nordic Conference on Computer-Human Interaction. ACM.

[18] Alexander, C. (2002). The nature of order: An essay on the art of building and the nature of the universe (Book Two: The Process of Creating Life). Berkeley, CA: The Center for Environmental Structure.

[19] J. M. Carroll and W. A. Kellogg. 1989. Artifact as theory-nexus: hermeneutics meets theory-based design. In Proceedings of the SIGCHI Conference on Human Factors in Computing Systems (CHI '89). Association for Computing Machinery, New York, NY, USA, 7-14.

[20] Theresa Cerratto-Pargman, Daniel Pargman and Bonnie Nardi, "The internet at the eco-village : Performing sustainbility in the twenty-first century," First Monday, vol. 21, no. 5, 2016.

[21] Jaz Hee-jeong Choi and Eli Blevis. 2010. HCI \& sustainable food cul- ture: A design framework for engagement. In NordiCHI '10. 112-117.

[22] Luigina Ciolfi and Gabriela Avram. 2016. Digital Social Interactions in the City: Reflecting on location-based social media, in Perng, S-Y and Kitchin, R. (Eds.), Code and the City, London: Routledge, 91-104.

[23] Cavell. 1969. Must We Mean What We Say? Cambridge: Cambridge University Press.

[24] Code, L. 2006. Ecological Thinking: the Politics of Epistemic Location. Oxford University Press, Oxford, UK.

[25] Davina Cooper, 2013. Everyday Utopias: The Conceptual Life of Promising Spaces. Duke University Press.
[26] Carl DiSalvo and Jonathan Lukens. 2009. Seeing the City rough Machines: Non-Anthropocentric Design and Youth Robotics. In Digital Cities 6: Concepts, Methods and Systems of Urban Informatics (Work- shop), Marcus Foth, Laura Forlano, and Hiromitsu Ha ori (Eds.). State College: Penn State University Press.

[27] Carl DiSalvo and Tom Jenkins. 2017. Fruit Are Heavy: A prototype Public IoT system to support Urban Foraging. DIS '17, Proceedings of the 2017 Conference on Designing Interactive Systems, Edinburgh, United Kingdom, 10-14 June, 2017. New York, NY: ACM, 541-553.

[28] Carl DiSalvo, Phoebe Sengers and Hronn Brynjarsdóttir. 2010. Mapping the landscape of sustainable HCI, Proceedings of the 28th international conference on Human factors in computing systems, CHI'2010. NY:ACM.

[29] Paul Dourish. 2006. Re-Space-ing Place: Place and Space Ten Years On. CSCW'06 (Banff, Alberta), 299-308

[30] Anthony Dunne and Fiona Raby. 2001. Design noir: The secret life of electronic objects. August Media, Boston.

[31] Anthony Dunne and Fiona Raby. 2013. Speculative Everything: Design, Fiction, and Social Dreaming. The MIT Press.

[32] Arturo Escobar. 2018. Designs for the Pluriverse: Radical Interdependence, $\mathrm{Au}-$ tonomy and the Making of Worlds. Durham and London: Duke University Press.

[33] Francesca Ferrando, "Posthumanism, Transhumanism, Antihumanism, Metahumanism, and New Materialisms: Differences and Relations," Existenz 8/2 (2013), 26-32.

[34] Laura Forlano. 2017. Posthumanism and Design, she ji The Journal of Design, Economics, and Innovation. 3, (1), 16-29.

[35] Roger Fowler. 1986. Linguistic Criticism. Oxford: Oxford University Press.

[36] Guo Freeman, Jeffrey Bardzell \& Shaowen Bardzell (2019) Open Source, Open Vision: The MakerPro Network and the Broadening of Participation in Setting Taiwan's IT Vision Agenda, Human-Computer Interaction, 34:5-6, 506-540, DOI: $10.1080 / 07370024.2018 .1555043$.

[37] Guo Freeman, Jeffrey Bardzell, Shaowen Bardzell, Szu-Yu (Cyn) Liu, Xi Lu, and Diandian Cao. 2019. Smart and Fermented Cities: An Approach to Placemaking in Urban Informatics. In Proceedings of the 2019 CHI Conference on Human Factors in Computing Systems (CHI '19). Association for Computing Machinery, New York, NY, USA, Paper 44, 1-13. DOI: https://doi.org/10.1145/3290605.3300274.

[38] Tony Fry. 2009. Design Futuring: Sustainability, Ethics and New Practice. Bloomsbury.

[39] Greta Gaard. 2011. Ecofeminism Revisited: Rejecting Essentialism and RePlacing Species in a Material Feminist Environmentalism. In Feminist Formations, Vol. 23 No. 2. John Hopkins University Press, 26-53.

[40] Greg Garrard. 2016 'The Environmental Humanities: Notes Towards a Summary for Policymakers', in The Routledge Companion to the Environmental Humanities, ed. U. Heise and J. Christensen, Routledge: 446-456.

[41] Lisa M Given, Denise Cantrell Winkler, and Kathryn Hopps-Wallis. 2017. Social Media for Social Good: A Study of Experiences and Opportunities in Rural Australia. In Proceedings of the 8th International Conference on Social Media \& Society. Article No. 7.

[42] John Gray. 2014. Hefting onto place: Intersecting Lives of Humans and Sheep on Scottish Hills Landscape. Anthrozoos: A Multidisciplinary Journal of the Interactions of People and Animals. 27:2, 219-234.

[43] Ghassan Hage. 2017. Is Racism an Environmental Threat? Polity Press.

[44] Maria Håkansson and Phoebe Sengers. 2013. Beyond being green: simple living families and ICT. In Proceedings of the SIGCHI Conference on Human Factors in Computing Systems - CHI '13, 2725.

[45] Donna J. Haraway. 2003. The Companion Species Manifesto: Dogs, People, and Significant Otherness, Chicago: Prickly Paradigm Press.

[46] Donna J. Haraway. 2016. Staying with the Trouble: Making Kin in the Chthulucene, Durham: Duke University Press.

[47] Steve Harrison and Paul Dourish. 1996. Re-place-ing space: the roles of place and space in collaborative systems. In Proceedings of the 1996 ACM conference on Computer supported cooperative work (CSCW'96). Association for Computing Machinery, New York, NY, USA, 67-76. DOI: https://doi.org/10.1145/240080. 240193.

[48] Steve Harrison, Deborah Tatar and Phoebe Sengers. 2007. The three paradigms of HCI. Proc. of EA CHI 2007. ACM, New York.

[49] Sara Heitlinger, Nick Bryan-Kinns, and Janis Jefferies. 2013. Sustainable HCI for grassroots urban food-growing communities. In OzCHI '13. 255-264.

[50] Sara Heitlinger. Marcus Foth., Rchel Clarke., Carl Disalvo, Ann Light and Laura Forlano. 2018. Avoiding Ecocidal Smart Cities: Participatory Design for Morethan-Human Futures. Proc. PDC 2018: 2-4.

[51] Tad Hirsch. 2014. Beyond Gardening: A New Approach to HCI and Urban Agriculture. In Eat, Cook, Grow: Mixing Human-Computer In- teractions with Human-Food Interactions, Jaz Hee-Jeong Choi, Marcus Foth, and Greg Hearn (Eds.). e MIT Press, Chapter 13, 227-242.

[52] Heather A. Horst and Daniel Miller (Eds.). 2012. Digital Anthropology. Berg.

[53] Ya-Xuan (NaiNai) Huang. 2018. 土拉客柑埛園用藥明. http://landdykecsa. blogspot.com/2018/07/2018.html?view=magazine. 
[54] IPCC. 2018. Summary for Policymakers. Global Warming of $1.5^{\circ}{ }^{\circ} \mathrm{C}$. An IPCC Special Report on the impacts of global warming of $1.5\left\{{ }^{\circ}\right\} \mathrm{C}$ above pre-industrial levels and related global greenhouse gas emission pathways, in the context of strengthening the global response to the threat of climate change, sustainable development, and efforts to eradicate poverty. Geneva: World Meteorological Organization. Available at: http://report.ipcc.ch/sr15/pdf/sr15_spm_final.pdf.

[55] ISO/IEC 9126-4: https://www.iso.org/standard/39752.html (revised 2016).

[56] Gopinnath Kannabiran. "Embodied Wellbeing": A Re-imagination of Sustainability and Desire in HCI. Dissertation. 2017.

[57] Lucy Kimbell. 2012. Rethinking Design Thinking: Part 2, Design and Culture, 4(2):129-148.

[58] Bran Knowles, Oliver Bates, and Maria Håkansson. 2018. This Changes Sustainable HCI. In Proceedings of the 2018 CHI Conference on Human Factors in Computing Systems - CHI '18, 1-12.

[59] Jeremy Lent. 2017. The Patterning Instinct.: A Cultural History of Humanity's Search for Meaning. LA: Prometheus Books.

[60] Ann Light. 2011. HCI as heterodoxy: Technologies of identity and the queering of interaction with computers, Interacting with Computers, vol 23 (5), Sept 2011

[61] Ann Light (2018) Who are We to Make Change? In Taking Action in a Changing World, interactions January-February 2018, p34-45 (https://dl.acm.org/citation cfm?id=3169128.

[62] Ann Light (2019) Design and Social Innovation at the Margins: Finding and Making Cultures of Plurality, J. Design and Culture.

[63] Ann Light and Yoko Akama. 2014. Structuring Future Social Relations: The Politics of Care in Participatory Practice, Proc. ACM PDC 2014, pp151-160.

[64] Ann Light and Yoko Akama. 2019. The Nature of 'Obligation' in Doing Design with Communities: Participation, Politics and Care (eds) Fisher, T. and Gamman, L. Tricky Design: ethics through things. London: Bloomsbury.

[65] Ann Light and Clodagh Miskelly. 2015. Sharing Economy vs Sharing Cultures? Designing for social, economic and environmental good, Interaction Design and Architecture(s) Journal - IxD\&A, no. 24, 49-62.

[66] Ann Light and Clodagh Miskelly, 2019. Platforms, Scales and Networks: Meshing a Local Sustainable Sharing Economy. JCSCW, Summer 2019.

[67] Ann Light, Alison Powell and Irina Shklovski. 2017. Design for Existential Crisis in the Anthropocene Age. C\&T'17.

[68] Ann Light, Kate Howland, Tom Hamilton, and David A Harley. 2017. The Meaning of Place in Supporting Sociality, Proc. DIS'17.

[69] Amber Lin. 2017. Land Dyke Feminist Family Farm: Women Create Farming Community. CommonWealth Magazine (Jun 2017). https://english.cw.com.tw/ article/article. action?id=1630.

[70] Silvia Lindtner, Shaowen Bardzell, and Jeffrey Bardzell. 2016. Reconstituting the Utopian Vision of Making: HCI After Technosolutionism. In Proceedings of the 2016 CHI Conference on Human Factors in Computing Systems (CHI '16). Association for Computing Machinery, New York, NY, USA, 1390-1402.

[71] Szu-Yu (Cyn) Liu, Shaowen Bardzell, and Jeffrey Bardzell. (2019a). Symbiotic Encounters: HCI and Sustainable Agriculture. Proc. of CHI2019. ACM: New York.

[72] Szu-Yu Liu, Jeffrey Bardzell, and Shaowen Bardzell (2019b). Decomposition as Design: Co-Creating (with) Natureculture. Proc. of TEI2019. ACM: New York.

[73] Szu-Yu Liu, Shaowen Bardzell, and Jeffrey Bardzell. (2018): Out of Control Reframing Sustainable HCI Using Permaculture. Proc. of LIMITS2018. ACM New York.

[74] Jen Liu, Daragh Byrne, and Laura Devendorf. 2018. Design for Collaborative Survival: An Inquiry into Human-Fungi Relationships. In Proceedings of the 2018 CHI Conference on Human Factors in Computing Systems (CHI '18). Association for Computing Machinery, New York, NY, USA, Paper 40, 1-13.

[75] Andrew S. Mathews. Landscapes and Throughscapes in Italian Forest Worlds Thinking Dramatically about the Anthropocene. Cultural Anthropology, Vol. 33, Issue 3, pp. 386-414. 2018.

[76] McCarthy \& Wright. 2004. Technology as Experience. Cambridge, MA: MIT Press.

[77] Daniel Miller and Don Slater. 2000. The Internet: An Ethnographic Approach (1 ed.). Bloomsbury Academic.

[78] Timothy Morton. 2016. Dark Ecology: For a Logic of Future Coexistence. Columbia University Press.

[79] Omar Mubin, Joshua Tubb, Mauricio Novoa, Mustafa Naseem, and Samia Razaq 2015. Understanding the Needs of Pakistani Farmers and the Prospects of an ICT Intervention. In CHI EA '15. 1109-1114.

[80] Bonnie Nardi. 2019. Design in the Age of Climate Change. She Ji: The Journal of Design, Economics, and Innovation, 5(1). 5-14

[81] Bonnie Nardi, Bill Tomlinson, Donald J. Patterson, Jay Chen, Daniel Pargman, Barath Raghavan, and Birgit Penzenstadler. 2018. Computing within limits. Communications of the ACM 61, 10: 86-93.

[82] Harold Nelson and Erik Stolterman. 2012. The Design Way. 2nd ed. Cambridge, MA: MIT Press.

[83] Don Norman. 1988. Design of Everyday Things. New York: Basic Books.

[84] William Odom. 2014."You Don't Have to Be a Gardener to Do Urban Agriculture”: Understanding Opportunities for Designing Interactive Technologies to
Support Urban Food Production. In Eat, Cook, Grow: Mixing Human-Computer Interactions with Human-Food Interactions. MIT Press, 177.

[85] Erick Oduor, Peninah Waweru, Jonathan Lenchner, and Carman Neustaedter. 2018. Practices and Technology Needs of a Network of Farmers in araka Nithi, Kenya. In CHI '18. 1-11.

[86] Charles Kay Ogden and Ivor Armstrong Richards. 1923. The Meaning of Meaning: A Study of the Influence of Language upon Thought and of the Science of Symbolism. Mariner Books.

[87] Kenneth R. Olwig. 2016. Performing on the Landscape versus Doing Landscape: Perambulatory Practice, Sight and the Sense of Belong. In Ways of Walking: Ethnography and Practice on Foot. Tim Ingold and Jo Lee Vergunst (eds.). Routledge.

[88] Marcel Proust. 1913. À la recherche du temps perdu. Gallimard.

[89] Maria Puig de la Bellacasa. 2016. Ecological thinking, material spirituality, and the poetics of infrastructure. In 'Boundary Objects and Beyond : Working with Leigh Star' eds Geoffrey Bowker, Stefan Timmermans, Adele Clarke, and Ellen Balka, MIT Press.

[90] Maria Puig de la Bellacasa. 2017. Matters of Care: Speculative Ethics in More than Human Worlds, University of Minnesota Press.

[91] Barath Raghavan, Bonnie Nardi, Sarah T Lovell, Juliet Norton, Bill Tomlinson, and Donald J Pa erson. 2016. Computational Agroecology: Sustainable Food Ecosystem Design. In CHI EA '16. 423-435.

[92] I.A. Richards. 1929. Practical Criticism. Harcourt Brace Janovich.

[93] Donald Schön. 1983. The Reflective Practitioner. United States: Basic Books.

[94] James C. Scott. 2017. Against the Grain: A Deep History of the Earliest States. Yale University Press.

[95] M. Six Silberman, Lisa Nathan, Bran Knowles, Roy Bendor, Adrian Clear, Maria Håkansson, Tawanna Dillahunt, and Jennifer Mankoff. 2014. Next steps for sustainable HCI. interactions 21, 5: 66-69.

[96] Herbert A. Simon. 1996. Sciences of the Artificial. 3rd ed. Cambridge, MA: MIT Press.

[97] Nancy Smith, Shaowen Bardzell, and Jeffrey Bardzell. (2017). Designing for Cohabitation: Naturecultures, Hybrids, and Decentering the Human in Design. Proc. of CHI2017. ACM: New York.

[98] Susan Leigh Star and Karen Ruhleder. 1996. Steps Toward an Ecology of Infrastructure: Design and Access for Large Information Spaces. Information System Research. 7(1)

[99] Charles Steinfield, Susan Wyche, Tian Cai, and Hastings Chiwasa. 2015. e Mobile Divide Revisited: Mobile Phone Use by Smallholder Farmers in Malawi. In ICTD

[100] Rosemary Steup, Arvind Santhanam, Marisa Logan, Lynn Dom- browski, and Norman Makoto Su. 2018. Growing Tiny Publics: Small Farmers' Social Movement Strategies. Proceedings of the ACM on Human-Computer Interaction CSCW (2018), Article No. 165.

[101] Yolande A.A. Strengers. 2011. Designing eco-feedback systems for everyday life, Proceedings of the SIGCHI Conference on Human Factors in Computing Systems, CHI'11,

[102] Lucy A. Suchman. 1987. Plans and Situated Actions. Cambridge: Cambridge University Press.

[103] Yen-Ling Tsai. Farming Odd Kin in Patchy Anthropocenes. Current Anthropology, Vol. 60, Supplement 20, August 2019.

[104] Yen-Ling Tsai, Isabelle Crabonell, Loelle Chevrier, and Anna Lowenhaupt Tsing. GOLDEN SNAIL OPERA: The More-Than-Human Performance of Friendly Farming on Taiwan's Lanyang Plain. Cultural Anthropology, Vol. 31, Issue 4, pp 520-544, 2016.

[105] Bill Tomlinson, Eli Blevis, Bonnie Nardi, Donald J. Patterson, M. Six Silberman, and Yue Pan. 2008. Collapse informatics and practice: Theory, method, and design. ACM Transactions on Computer-Human Interaction 20, 4: 1-26.

[106] Cameron Tonkinwise (2014) How We Intend to Future: Review of Anthony Dunne and Fiona Raby, Speculative Everything: Design, Fiction, and Social Dreaming, Design Philosophy Papers, 12:2, 169-187.

107] Transition Towns: https://transitionnetwork.org/.

108] Anna Lowenhaupt Tsing, Andrew S. Mathews, and Nils Bubandt. Patchy Anthropocene: Landscape Structure, Multispecies History, and the Retooling of Anthropology. An Introduction to Supplement 20. Current Anthropology, Vol. 60, Supplement 20, August 2019.

[109] Vasilis Vlachokyriakos, Clara Crivellaro; Peter Wright; and Patrick Olivier. 2018. Infrastructuring the Solidarity Economy: Unpacking Strategies and Tactics in Designing Social Innovation. CHI '18, Proceedings of the $2018 \mathrm{CHI}$ conference on human factors in computing systems, Montreal QC, Canada, 21-26 April 2018. New York, NY: ACM, pp. 481-493.

[110] Sagar K. Wadkar, Khajan Singh, Asif Mohammad, and Shivaji D. Ar- gade. 2017. Sustainability of the Rural ICT Project: a Case Study of aAQUA e-Agriservice, Maharashtra, India. In ICEGOV '17. 384-390.

[111] Karen J. Warren (ed.). Ecofeminism: Women, Culture, and Nature. Indiana University Press, 1997

[112] Karen J. Warren. Ecofeminist Philosophy: A Western Perspective on What It is and Why It Matters. Rowman \& Littlefield Publishers, Inc. 2000 
[113] Charlotte Webster. 2019. The origins and rise of the Extinction Symbol. Ecohustler. 9 Apr 2019: https://ecohustler.com/article/the-origins-and-rise- of-theextinction-symbol.

[114] Terry Winograd and Fernando Flores. 1986. Understanding Computers and Cognition. Ablex Publishing.
[115] Kathryn Yusoff. 2019. A Billion Black Anthropocenes, Minnesota, MI: University of Minnesota Press.

[116] John Zimmerman, Jodi Forlizzi, and Shelley Evenson. 2007. Research through design as a method for interaction design research in HCI. In Proceedings of the SIGCHI Conference on Human Factors in Computing Systems (CHI '07). Association for Computing Machinery, New York, NY, USA, 493-502. 